\title{
Qualidade de vida e estresse gerencial "pós-choque de gestão": 0 caso da Copasa-MG*
}

\author{
Kely César Martins de Paiva** \\ João Henrique Couto***
}

Sumário: 1. Introdução; 2. Referencial teórico; 3. Metodologia; 4. Apresentação e análise dos dados; 5 . Considerações finais.

Summary: 1. Introduction; 2. Theoretical framework; 3. Methodology; 4. Data presentation and analysis; 5. Final remarks.

Palavras-chave: qualidade de vida no trabalho; estresse ocupacional; gerente; gerência; "choque de gestão".

KEY WORDs: quality of life at he workplace; occupational stress; manager; management; 'management shock'.

Este artigo descreve e analisa o corpo gerencial de uma empresa pública no que diz respeito às variáveis de qualidade de vida no trabalho e de estresse ocupacional, tendo em vista o contexto de reestruturação produtiva e seus multivariados impactos nas atividades dos gestores e nos significados atribuídos a essas experiências de trabalho, implicando desgastes à saúde dos indivíduos. Foi feita uma pesquisa descritiva, de enfoque quantitativo e qualitativo. O questionário foi respondido por 96 dos 144 gestores. De uma maneira geral, a qualidade de vida dos pesquisados apresenta-se com níveis satisfatórios. A partir de uma análise conjunta dos resultados, aponta-se para uma realidade de estresse. Assim, a estruturação de políticas e práticas de gestão de pessoas mais abrangentes é necessária para a identificação, a desmistificação e o monitoramento do estresse ocupacional entre os gerentes da empresa, passando por pesquisas mais específicas de diagnóstico. Tais atividades são recursos adjacentes à

\footnotetext{
* Artigo recebido em out. 2007 e aceito em jul. 2008.

** Doutora em administração. Professora e pesquisadora da Faculdade Novos Horizontes. Endereço: Rua Alvarenga Peixoto, 1270 - Bairro Santo Agostinho - CEP 30121-180, Belo Horizonte, MG, Brasil.E-mail: serra.bh@terra.com.br ou kely@unihorizontes.br.

*** Economista e especialista em gestão estratégica de negócios. Analista de RI da Copasa-MG. Endereço: Rua Mar de Espanha, 453 — Bairro Santo Antônio — CEP 30330-270, Belo Horizonte, MG, Brasil. E-mail: joaohenrique.couto@copasa.com.br.
} 
reestruturação produtiva em curso, pois referem-se à gestão da força de trabalho e à mediação de conflitos.

\section{Quality of life and 'post-management shock' managerial stress: the Copasa-MG case}

This article describes and analyzes the management team of a public company in terms of quality of life at the workplace and occupational stress variables. The context of reorganization includes multiple impacts in the managers' activities and the meanings they give to this experience, with implications to their health. A descriptive survey was performed considering both quantitative and qualitative approaches among 144 managers. Of those, 96 (the sample) answered the questionnaire, which was the main data collection tool. In general terms, the levels of quality of life at the workplace were satisfactory. However, occupational stress was identified. As a result, there is a need to structure people management policies and practices in order to identify, demystify and monitor occupational stress among managers, including more specific diagnostic research. These activities are additional resources to the productive reorganization in course, therefore they are connected to the management of the work force and of conflicts.

\section{Introdução}

Este artigo descreve e analisa o corpo gerencial de uma empresa pública, a Companhia de Saneamento de Minas Gerais (Copasa-MG), depois da reestruturação produtiva promovida pelo governo estadual, no que diz respeito às variáveis de qualidade de vida no trabalho e de estresse ocupacional, tendo em vista os multivariados impactos que os sujeitos vêm sofrendo em função das necessidades de adaptação individual e grupal e superação de objetivos organizacionais, decorrentes das alterações promovidas em suas atividades e também nos significados dessas experiências de trabalho, provocando desgastes, tanto físicos quanto mentais, à saúde dos indivíduos. O "choque de gestão" teve como escopo uma sensível melhora nos resultados da organização, trazendo modernas técnicas de gestão da administração privada para a esfera pública e, com isso, revertendo o quadro de prejuízos observados em anos anteriores e tornando-a a empresa de saneamento com a maior rentabilidade sobre o patrimônio líquido do Brasil em 2004 (Álvares, 2005).

Entretanto, essa mudança gerou uma forte cobrança sobre o quadro gerencial da empresa, forçando-o a se adaptar a uma realidade mais competitiva. O gerente é o elo entre a alta direção da empresa e o nível operacional, sendo responsável pela harmonia em termos de alinhamento estratégico. Segundo Von Sperling (2002:42), o gestor possui uma função estratégica fundamental 
para que a empresa alcance suas metas, já que ele é o responsável pela implementação dos processos de modernização e reestruturação organizacional. Segundo a autora, o gerente deve aprender "novos conceitos a respeito das relações entre empresa e cliente, trabalho em equipe, cooperação e participação". Ele também deve aprender a "criar, inovar, tentar e errar", sendo uma pessoa dinâmica e ativa. Dessa forma, o gerente na modernidade tem um perfil extremamente exigente: ele deve ser capaz de responder a todos esses anseios, sob pena de ser tachado pela empresa, ou até por ele mesmo, como um fracassado. De acordo com Motta (1995), devido às exigências do mercado, o gestor atualmente pode ser chamado de "super-homem gerencial". Verifica-se assim uma forte pressão, por parte principalmente da empresa, sobre o sujeito que exerce a função gerencial.

No que tange às resistências, conforme Lima-Filho e colaboradores (2005), quando o assunto é mudança existem várias barreiras peculiares ao ambiente público. Segundo o autor, uma reestruturação organizacional em um ambiente tradicionalmente adverso à mudança torna-se condição suficiente para a instauração de crises, que se estendem do maior posto de comando da empresa até o menor grau hierárquico. Assim, segundo Rodrigues (1991:57), o gestor precisa ser extremamente dinâmico, preparado para grandes desafios, "ser especulador, jogador, filósofo, competitivo, cooperativo, jovial, desprovido de preconceitos", ou conforme Pereira e colaboradores (2003) ser uma pessoa polivalente, que saiba aprender a aprender e a fazer.

A Copasa-MG iniciou um processo de reestruturação organizacional no ano de 2003 que promoveu a abertura de espaços para uma cultura competitiva na empresa, onde não bastava para o gerente ser o antigo chefe, aquela pessoa inflexível que só sabia mandar (Castro e colaboradores, 2002), mas sim um líder, flexível e competente. Esse líder deve saber lidar com um grande número de novos e complexos papéis, diante do moderno contexto organizacional em que está inserido (Rodrigues, 1991). Esse novo papel é um grande desafio para a classe gerencial como um todo; entretanto, mediante o impasse observado entre a cultura organizacional que prevalecia antigamente e as fortes pressões atuais para a eficiência, para os gerentes das empresas públicas os impactos podem ser ainda maiores, conforme Von Sperling (2002:47) constata: "os gerentes públicos têm sentido os impactos de todas essas mudanças, talvez até mais fortemente do que os outros gerentes".

Conforme salienta Aktouf (2005), discutir as transformações e as peculiaridades da função gerencial no início do século XXI é uma tarefa original, difícil e de utilidade incontestável, tendo em vista os questionamentos enfrentados pela gestão contemporânea. Assim, vale a pena analisar como se encon- 
tram os gestores da organização sob as óticas da qualidade de vida no trabalho (QVT), e do estresse ocupacional, já que tais perspectivas poderão trazer importantes contribuições, de cunho prático e conceitual, principalmente nas instâncias social e individual do profissional, diante do novo ambiente em que se encontra. Para tanto, nas referências conceituais, as temáticas centrais do artigo - função gerencial, QVT e estresse ocupacional — são discutidas e, em seguida, apresenta-se a metodologia adotada na pesquisa. Os dados foram descritos e analisados e, ao final, foram feitas considerações sobre a investigação e as possibilidades de atuação da organização nesse sentido, além de sugestões para outras pesquisas, com vistas à ampliação e ao aprofundamento das discussões pertinentes a tais construtos.

\section{Referencial teórico}

\section{Função gerencial}

Um dos precursores dos estudos sobre gerência foi Taylor (1970), segundo o qual o papel do gestor começou a ser delineado pelas suas responsabilidades pela concepção e andamento do processo produtivo. A partir da observação direta e do estudo do trabalho de operários, o autor delineou o conceito de "supervisão funcional", que permeava seus princípios "científicos" de administração. No entanto, o sistema taylorista foi alvo de muitas críticas por desconsiderar o indivíduo como um ser humano dotado de necessidades e desejos, conforme salientam Braverman (1981) e Morgan (1996).

Fayol (1990) percebeu que as características da função eram mais complexas e que, além de ter autoridade e responsabilidade sobre o processo produtivo, o gerente deveria ter iniciativa e colaborar com a subordinação dos interesses individuais aos organizacionais e estar atento à remuneração do pessoal, de forma a aliar a percepção de eqüidade e de estabilidade, promovendo sua satisfação e o espírito de equipe. Conforme o autor, o gerente é chamado, ou obrigado, a responder positivamente pelas suas novas responsabilidades: administrar, prever, organizar, comandar, coordenar e controlar. Com o passar dos tempos, a forma de realizar seu papel, tomando decisões, sofreu grandes mudanças devido ao grande volume de informações estratégicas disponíveis e requeridas no ambiente empresarial, não tendo mais espaço as decisões de cunho estritamente pessoais, conforme salienta Schein (1994). Nesse sentido, o administrador ocupa um espaço formal na burocracia, detendo a especialização e o poder legítimo que o cargo lhe imbui (Weber, 1946). O cargo de ge- 
rente, na perspectiva weberiana, é legitimado tanto pelo seu posicionamento na hierarquia como pela meritocracia, competência técnica, profissionalização de seus membros e pela separação entre administração da organização e sua propriedade, necessitando de racionalidade e funcionalidade.

Já Simon (1965), autor que privilegia os aspectos relacionados ao processo decisório, compreende que o gerente é um tomador de decisões, e que no exercício da sua função precisa ser capaz de entender as situações e os problemas organizacionais, identificar suas causas, criar alternativas, avaliá-las, escolher a mais satisfatória, colocá-la em prática e controlar seus resultados. A questão da eficácia também é destacada por Drucker (1967): num contexto de aumento da concorrência, aos trabalhadores manuais basta a eficiência, já para o gerente a eficácia é o elemento central, associando-se diretamente ao alcance de resultados.

Outra contribuição conceitual importante sobre a função gerencial refere-se à teoria de papéis de Mintzberg (1986). Segundo a lógica desse autor, os papéis do gestor circunscrevem-se a basicamente três naturezas: papéis interpessoais, informacionais e decisórios, e os primeiros promovem o desempenho dos segundos, e ambos permitem a execução dos terceiros. A partir daí, o autor esclareceu a complexidade do trabalho gerencial: o ritmo intenso; a brevidade, a variedade e a descontinuidade das tarefas; a orientação para a ação e para resultados; a execução de rotinas, rituais e cerimônias; a preferência por comunicações verbais; a organização do tempo; o processamento de informações e a tomada de decisões, incluindo-se aqui o uso da intuição.

Assim, o gestor busca, por vários meios, a cooperação dos membros rumo ao atingimento dos objetivos organizacionais. Nesse sentido, Barnard (1971) percebe o gerente como responsável pela promoção dessa cooperação e, segundo o autor, ele cria e mantém um sistema de comunicação que permeia as faces formal e informal da empresa como estratégia para ensejar sua eficácia, tangenciando aspectos como motivação e liderança. Para Barnard (1971), sob a responsabilidade gerencial está a formulação e a definição de propósitos, objetivos e fins da organização, de maneira tal que se mantenha uma união íntima entre pessoas e organização. Assumir o papel de mediador entre os dois últimos atores sociais depende muito da personalidade do profissional e de seu envolvimento com o exercício da função. Atento a esses aspectos no ambiente intra-organizacional, McClelland (1987) delineou uma teoria na qual as pessoas se motivam para adotar determinados comportamentos em função de três tipos de necessidades: de realização, de afiliação e de poder. No caso dos gerentes, o autor salienta que a necessidade de poder é mais aguçada, podendo estar voltado para si mesmo ou para os outros. No exercício do poder, 
os gestores utilizam diversas táticas, como ser cauteloso e aceitar conselhos, cultivar alianças, garantir espaços de manobras, deter informações, manipular o tempo, desenvolver a autodramatização, revelar confiança pela aparência e evitar emoções, sentimentos e amizades.

Percebendo a necessidade de humanizar o ambiente organizacional, Likert (1971) aponta para a falência do gerente tipicamente autoritário, diante da concorrência e das ineficiências produtivas. Nesse contexto, o autor afirma que é preciso considerar: a natureza das forças motivacionais, do processo de comunicação, do processo influência-interação, do processo decisório, da formação de metas, dos processos de controle e das características do desempenho individual-grupal, para que seja possível a consecução dos fins empresariais. Para o efetivo exercício da função gerencial são necessárias habilidades diferenciadas que Katz (1986) categorizou como conceituais, humanas e técnicas, que variam à medida que o gerente progride pelos diversos níveis hierárquicos organizacionais. Nessa abordagem, à proporção que o gestor alcança níveis hierárquicos mais altos, ele carece de habilidades mais conceituais e menos técnicas, mantendo-se relativamente constante na sua carreira a utilização de habilidades humanas, já que em todo o percurso para atingir suas metas ele depende essencialmente do trabalho dos subordinados e, portanto, da relação que mantém com eles.

O caráter multifacetado da função gerencial é também destacado por Hill (1993). A autora sublinha que tal natureza diz respeito tanto aos meios e processos utilizados, quanto aos fins e expectativas às quais deve, ou pelo menos tenta, estar atento e atingir. Ela destaca as características de variedade e fragmentação do trabalho do gerente ante à sua dependência em relação aos outros atores sociais, principalmente os subordinados. Atingir objetivos tornase tarefa árdua, pois deve conjugar esforços variados: psicológicos, técnicos e outros ligados às relações de poder. A autora enfatiza as relações de poder e como elas são delineadas à medida que o sujeito se adapta às responsabilidades e à autoridade inerentes ao cargo e, ao mesmo tempo, se organiza psiquicamente para seus "sucessos" e "fracassos". Caminha-se, assim, para a identificação e compreensão de repertórios de símbolos, códigos e imagens que estruturam e são estruturados pelo "homem administrativo", ser ambíguo que constrói sua identidade também a partir da descoberta de estratégias que promovem sua sobrevivência e a construção de carreira em organizações cada vez mais instáveis (Davel e Melo, 2005), em virtude dos constantes processos de reestruturação produtiva. Nesse sentido, Grum (1995) chama atenção para o fato de que gerentes têm se apropriado do discurso e das terminologias 
próprias das "novas" tecnologias gerenciais, para construir um campo de ação social que assegure sua sobrevivência no espaço organizacional.

Diante de tantas contradições e fragmentações, muitos gestores acabam por vivenciar um certo desânimo quando percebem o preço a ser pago pelas suas necessidades de poder, status e realização pessoal. Diante das constantes reestruturações organizacionais, Rouleau (2000) salienta sua constituição por movimentos cíclicos de racionalização e flexibilização, implicando demissão e intensificação do trabalho gerencial, sendo este último fato um dos determinantes do "mal-estar" desses profissionais (Davel e Melo, 2005; Rouleau, 2005), o qual não se restringe à organização, mas transcende para outros espaços da vida privada.

Em relação ao papel da gerência no setor público, Tohá e Solari (1997) afirmam que ele tem sido reformulado ao longo do tempo, tendo em vista as mudanças ocorridas nas instituições em diversos países na atualidade. Esta reformulação da gerência pública tem como objetivo a otimização dos recursos públicos, aumentando a eficiência da máquina estatal, sem o esquecimento do princípio da eqüidade, que também norteia as decisões nessas organizações. O setor público possui algumas especificidades, que devem ser observadas para que haja uma melhor distinção quando confrontado com o setor privado. Assim, Tohá e Solari (1997:12) sublinham que:

sustentamos que esta [a gerência pública] tem especificidades, porque as instituições públicas têm objetivos, normativas e produtos distintos aos das privadas, se relacionam de outro modo com seus usuários e têm recursos de origem e natureza especial. As motivações e a vocação de um gerente público são outras que as de um privado. Também existem diferenças entre os conhecimentos requeridos e as exigências pleiteadas. Há que se supor, então, que o desenvolvimento da gerência pública não passa por adotar, ou somente adaptar, os avanços da gerência privada.

Os gerentes de empresas públicas, de acordo com essa tendência, devem procurar a máxima eficiência na administração do "negócio", conforme os moldes da gestão de empresas privadas, nas quais o resultado é um dos principais indicadores de sucesso. Todavia, eles necessitam também ter discernimento e capacidade crítica para saber diferenciar o mundo público do privado, cabendo-lhes adequar as contribuições de sua função à sua realidade.

Por fim, estudos mais recentes têm apontado para outras dimensões referentes à função gerencial. Melo (1999) e Melo e colaboradores (2005) sublinham a ausência de consenso sobre o perfil requerido mesmo entre os 
próprios gerentes. A autora constatou que há uma grande diversidade de opiniões sobre os desafios que a eles se impõem e quais são as características e habilidades que eles precisam ter para exercer suas funções. Retomando as questões relacionadas a poder, Melo (1999) e Melo e colaboradores (2005) apontam controvérsias em torno do papel gerencial: o crédito atribuído a esse profissional pelo desempenho da organização e as acusações sobre sua contribuição para a manutenção das relações de poder e de seu trabalho a favor da regulação das contradições da vida corporativa. Motta (1995), por sua vez, contribui para a discussão ao apresentar um conjunto de habilidades relacionadas a dimensões do trabalho do gestor: dimensão organizacional (conhecer o contexto em que a organização atua, sua missão, objetivos estratégicos e cultura), dimensão interpessoal (possuir habilidades de interação e de comunicação) e dimensão individual (possuir determinadas qualidades individuais). Todas essas dimensões relacionadas mantêm conexão direta com as variáveis abordadas na qualidade de vida no trabalho e no estresse ocupacional.

\section{Qualidade de vida no trabalho}

Berndt e Coimbra (1995) afirmam que há uma necessidade de se alterarem valores da sociedade pós-industrial. Os elevados custos de despoluições têm levado a uma preocupação com tecnologias brandas, com o desenvolvimento auto-sustentável e com a utilização preferencial de recursos renováveis. Assim, vem ocorrendo uma mudança na atribuição de valor em relação ao trabalho, que passa de sacrifício ou venda de força física ou intelectual a atividade prazerosa de realização do potencial de cada ser humano. Essa concepção, segundo os autores, é a raiz da qualidade de vida, ao contrário do que eles chamam de visão pervertida de crescimento econômico destrutivo. Os valores de realização humana e de crescimento interior da pessoa são considerados, nas propostas de novas teorias econômicas, exigindo mudanças nos paradigmas das atuais.

A QVT, inicialmente, foi definida em termos de reação e/ou percepção das pessoas em relação ao trabalho, particularmente resultados individuais relacionados à satisfação com as tarefas e saúde mental. O foco era dirigido às conseqüências pessoais da experiência de trabalho e à forma de enriquecer tal atividade com vistas à satisfação de necessidades individuais. Mais tarde, QVT foi concebida como uma abordagem, ou um método. Ela passou a ser definida em termos de técnicas específicas usadas para reformular o trabalho, como o enriquecimento de cargos e tarefas, grupos de trabalho autônomos e 
semi-autônomos, comissões, entre outros. Em seguida, QVT foi definida como um movimento, uma ideologia a ser promovida em função de seus valores sociais positivos. Termos como "administração participativa" e "democracia industrial" caracterizam essa ideologia. Por fim, QVT também foi vista como um conceito global envolvendo todos os tipos de programas e perspectivas que visam à competição externa, problemas de qualidade ou mesmo com insatisfação de empregados. Esse conceito, segundo Huse e Cummings (1985), leva as pessoas à confusão acerca do que QVT realmente é, e cria expectativas não realísticas acerca de sua abrangência e de seus resultados. Assim, a qualidade de vida no trabalho, conceitualmente, evoluiu por meio de pesquisas e intervenções em empresas, procurando medir, de forma pessoal, a satisfação do indivíduo em relação ao seu trabalho e saúde mental.

Após leitura de clássicos como Walton (1973), Hackman e Oldham (1975), Lippitt (1978), Westley (1979), Thériault (1980), Nadler e Lawler (1983), Davis e Werther (1983) e Huse e Cummings (1985), a abordagem da qualidade de vida no trabalho de Hackman e Oldham (1975) foi considerada a mais apropriada para o desenvolvimento deste artigo, dada a reestruturação organizacional na empresa e no nível hierárquico abordados.

Na visão de Hackman e Oldham (1975), a qualidade de vida no trabalho está relacionada às características das atividades exercidas pelos funcionários no ambiente de trabalho. Os autores propõem uma teoria relacionada às dimensões básicas da tarefa, que por sua vez influenciam psicologicamente o empregado e conseqüentemente a sua produtividade dentro da organização. A necessidade de crescimento na organização também influencia os determinantes da qualidade de vida no trabalho. As dimensões da tarefa foram classificadas do seguinte modo: variedade de habilidades, identidade da tarefa, significado da tarefa, inter-relacionamento, autonomia, feedback intrínseco e feedback extrínseco. Os estados psicológicos críticos, que relacionam-se com a capacidade analítica do papel do próprio indivíduo dentro da organização e sua conexão com a atividade exercida, compreendem três aspectos: significância percebida do trabalho, responsabilidade percebida pelo resultado do trabalho e conhecimento dos resultados do trabalho. Já os resultados pessoais e de trabalho são: satisfação geral, motivação interna ao trabalho, produção de trabalho de alta qualidade, absenteísmo e rotatividade baixos, e satisfações específicas como possibilidade de crescimento, supervisão, segurança, remuneração e ambiente social.

Moraes e Kilimnik (1994) propuseram uma mudança no modelo de Hackman e Oldham, fundamentados nos resultados de pesquisas próprias realizadas no Brasil, onde perceberam que as variáveis denominadas satisfações 
específicas influenciavam os estados psicológicos críticos, além de serem, ao mesmo tempo, resultado dos mesmos. Seguindo essa linha de pensamento, os autores apresentaram uma alteração no modelo de Hackman e Oldham (1975), deslocando as "satisfações específicas" do grupo "resultados pessoais de trabalho" para junto da "necessidade individual de crescimento", observando-se sua influência em toda a cadeia de variáveis determinantes da QVT.

Por fim, Moraes e Kilimnik (1996) apontam que as diferenças individuais em termos de traços de personalidade, o não atendimento das necessidades básicas via trabalho, a conseqüente luta por salários e segurança e a percepção da conexão entre desempenho e recompensas via trabalho, entre outros fatores, fazem dessa abordagem uma das mais indicadas para diagnosticar QVT.

\section{Estresse ocupacional}

O conceito de estresse foi desenvolvido a partir de diferentes perspectivas de pesquisas de diversos autores, como Selye (1946, 1974), Goldberg (1978), Albrecht (1979), Cummings e Cooper (1979), Jamal (1990), Cooper e colaboradores $(1988,1995,1996)$, entre outros. Cooper e colaboradores (1996) propõem uma síntese em torno da questão do conceito de estresse ocupacional na qual afirmam que os pesquisadores da área focalizam um dos três aspectos a seguir:

v estresse como variável dependente - uma resposta a um estímulo perturbador;

v estresse como variável independente - um estímulo externo;

v estresse como variável interveniente - uma abordagem interacionista que enfatiza a forma como os indivíduos percebem e reagem às situações.

A visão do estresse como variável interveniente, como parte de um fenômeno dinâmico e de um processo complexo, é a que predomina nas pesquisas realizadas recentemente (Cooper e colaboradores, 1996) e a adotada para este artigo.

Segundo Moraes e Kilimnik (1994), o fenômeno do estresse ocupacional pode ser avaliado em termos de quatro variáveis: fontes de pressão no trabalho; personalidade do indivíduo; estratégias de combate e/ou defesa contra o estresse desenvolvidas pelas pessoas; e sintomas físicos e mentais manifestos no processo. Para os autores, as duas primeiras variáveis afetam sensivelmente as duas últimas. 
Com relação à primeira variável, fontes de pressão no trabalho, Cooper e colaboradores $(1988,1995,1996)$ designam seis categorias de agentes estressores: os fatores intrínsecos ao trabalho; o papel do indivíduo na organização; os relacionamentos interpessoais; a satisfação do trabalhador em termos de carreira e perspectivas futuras; o clima e a estrutura organizacionais; e a interface casa-trabalho do indivíduo. Tais fontes de estresse são mediadas pelas características individuais das pessoas e pelas "estratégias de combate" adotadas pelos indivíduos.

Por outro lado, os autores afirmam que essas fontes de pressão levam o indivíduo a manifestar sintomas físicos e mentais de estresse, que dependem de diferenças individuais tanto em ajustamento de personalidade, maturidade e capacidade de respostas, como estrutura física e cultural e ambiente social. Tais sintomas se mostram individualmente (aumento da pressão arterial, dores nos ombros e coluna, depressão, consumo de álcool, irritabilidade acentuada, alienação, apatia, ansiedade etc.) e no âmbito organizacional (absenteísmo, rotatividade, dificuldades nas relações industriais, queda na qualidade e na produtividade etc.). Esses sinais podem levar, respectivamente, ao desenvolvimento de patologias físicas e mentais (problemas de coração, úlceras, gastrites, esgotamento etc.) e de disfunções organizacionais (greves, acidentes, sabotagem etc.). Caracteriza-se, assim, o modelo dinâmico do estresse ocupacional de Cooper e colaboradores (1988), útil na identificação dos fatores de pressão e das estratégias de combate/defesa contra o estresse adotadas pelos indivíduos.

A personalidade do indivíduo também age sobre a possibilidade de aparecimento de sintomas físicos e mentais atribuídos ao estresse. Em uma mesma situação, as pessoas podem agir de formas diferenciadas devido a características peculiares de suas personalidades. Friedman e Rosenman (1974) propuseram duas categorias de personalidade: tipo A, mais propensos ao estresse, pessoas impacientes, apressadas, competitivas, ansiosas, perfeccionistas, que levam a vida em ritmo acelerado, e se sentem culpadas quando descansam ou relaxam; e tipo $B$, referente a indivíduos que não sentem necessidade de impressionar terceiros, que são capazes de trabalhar sem agitação, relaxam sem sentimento de culpa, e não padecem de impaciência ou do senso de urgência, assim, são menos propensos ao estresse. Outra característica de personalidade relevante é chamada de "locus de controle". Ao desenvolver esse conceito, Rotter (1966) tentou avaliar a extensão do controle que os indivíduos julgavam ter sobre determinadas situações e sua reação a elas. Pessoas que possuem um locus de controle interno acreditam que têm domínio sobre o que acontece, e suas decisões e ações influenciam seus resultados pessoais. São, assim, menos 
susceptíveis ao estresse. Em contraste, pessoas categorizadas como de locus de controle externo, mais propensas ao estresse, visualizam uma pequena e restrita possibilidade de influência sobre os eventos que as atingem, constituindo tais fatores determinantes da maior parte de seus resultados. No campo da educação, as pesquisas de Rotter (1966) indicaram uma associação freqüente entre os profissionais acadêmicos com locus de controle interno e sucesso profissional e grande motivação para realização. Tanto as comparações entre tipos A e B quanto a concepção de locus de controle se encaixam num contínuo entre dois tipos contrastantes de personalidade. Não remete à existência apenas dos dois tipos puros, mas, sim, a uma tendência entre dois pontos. Tendo em vista que tipo de personalidade (A e B) e locus de controle (interno ou externo) são características individuais independentes entre si, sua associação interna nas pessoas terá impactos decisivos na determinação de estratégias de defesa e/ou combate contra o estresse.

Por tais estratégias entende-se um esforço cognitivo e comportamental do indivíduo na tentativa de gerenciar tanto o ambiente quanto as demandas internas e os conflitos que o possam estar afetando (Aldwin e colaboradores, 1981). As estratégias podem ser também compreendidas como tentativas ativas e/ou passivas do ser humano no sentido de responder, reduzir impactos ou mesmo eliminar ameaças (Dewe, 1992).

\section{Metodologia}

A pesquisa realizada pode ser considerada de natureza quantitativa e qualitativa. Quantitativa, devido ao seu caráter descritivo, em que se procura identificar incidência e distribuição de características da amostra (Kerlinger, 1980), passíveis de ser estendidas à população, neste caso, de gerentes da organização abordada (Demo, 2002); e qualitativa, porque se apóia numa visão amplificada, num olhar diferenciado sobre a realidade investigada, conforme salienta Demo (2002).

Diversos instrumentos foram utilizados para coleta de dados, conforme tipificação de Bruyne (1977):

- pesquisa e análise documental, para acessar dados secundários, como dados históricos e dados formais sobre o "choque de gestão", dados acerca das políticas de gestão de pessoas etc.;

จ questionário, que aborda variáveis de QVT, estresse, dados demográficos e funcionais;

マ observação direta, para verificação e controle de resultados. 
Sobre a relação população/amostra, convém sublinhar que o total de gerentes na empresa é de cerca de 144. Para cada um deles foi entregue um questionário e 96 deles retornaram preenchidos. Foi esclarecido aos gerentes que não se tratava de um instrumento institucional de avaliação, mas que suas respostas seriam mantidas em absoluto sigilo e que subsidiariam a reflexão e a formação de um trabalho acadêmico.

O questionário foi o principal instrumento de coleta de dados, e ele se desdobrou em três partes: dados demográficos, dados sobre qualidade de vida e dados sobre estresse ocupacional. Ao final, o gerente tinha um espaço para fazer comentários e sugestões.

Os dados coletados foram tratados estatisticamente e analisados conforme se segue.

\section{Apresentação e análise dos dados}

\section{Dados demográficos}

Por meio da pesquisa com os gerentes da Copasa-MG, observa-se, a partir da amostra estudada, que $92 \%$ dos cargos gerenciais são ocupados por pessoas do sexo masculino. Assim, a empresa possui em seu quadro gerencial um número muito reduzido de mulheres em posição de comando, explicado em parte pelas próprias características (entre elas a cultura) das empresas industriais que iniciaram suas operações nos anos 1960 e 1970, momento no qual os cargos de gerente eram ocupados em sua maioria por engenheiros, representados majoritariamente por homens.

Em relação à escolaridade dos gerentes, contatou-se que a grande maioria (59\%) possui especialização completa. Nota-se também que $26 \%$ dos abordados possui apenas graduação, $6 \%$ mestrado incompleto, $5 \%$ especialização incompleta e $1 \%$ doutorado incompleto.

Analisando a faixa etária dos gerentes da empresa, nota-se que $81 \%$ dos abordados possuem mais de 46 anos de idade, seguidos por 14\% que possuem entre 41 e 45 anos e 5\% entre 36 e 40 anos. É interessante ressaltar a ausência de funcionários mais jovens em cargos de chefia, passível de compreensão em virtude dos processos seletivos gerenciais, nos quais os pré-requisitos para concorrer a tais cargos passam por um tempo mínimo na empresa em cargos de nível superior e por um enquadramento mínimo requerido em altos níveis, como por exemplo, ser analista sênior. Entretanto, em fevereiro de 2006, o 
último pré-requisito foi abolido por norma interna, o que pode significar uma mudança no perfil dos gerentes nos próximos anos.

Quanto ao estado civil, observa-se que $85 \%$ são casados, seguidos por $5 \%$ que são solteiros, $4 \%$ divorciados, $3 \%$ separados, $2 \%$ outros e $1 \%$ de viúvos.

No que tange ao tempo na empresa, percebe-se que metade dos gerentes (50\%) está há mais de 25 anos na empresa. Observa-se também que 26\% dos gerentes estão entre 20 e 25 anos na empresa, $18 \%$ estão entre 15 e 20 anos e 6\% estão entre 10 e 15 anos. Esses dados mostram que a maioria do quadro gerencial possui grande experiência no interior da própria empresa.

Já o tempo no cargo mostra certo equilíbrio entre as faixas delimitadas, mas destaca-se que a maioria dos questionados, 24\%, está há mais de 12 anos no cargo. Outra constatação relevante refere-se aos gerentes que estão há menos de um ano no cargo, que correspondem a $20 \%$ dos mesmos, percentual muito significativo que mostra uma certa rotatividade nos cargos gerenciais. $\mathrm{O}$ resultado tem relação com uma norma da empresa, editada em 2005, na qual delimitava-se um prazo máximo de oito anos para todos os gerentes permanecerem no mesmo cargo, e após esse período, caso quisessem manter o status quo, deveriam entrar no processo seletivo gerencial. O restante da amostra evidenciou que $21 \%$ dos gerentes estão entre dois e quatro anos no cargo, $16 \%$ entre quatro e oito anos, $11 \%$ entre um e dois anos e $8 \%$ entre oito e 12 anos.

Sobre sedentarismo, pode-se verificar que $35 \%$ realizam alguma atividade física na semana.

Apenas $9 \%$ da amostra estudada tem o fumo como um vício, e $91 \%$ são não fumantes. $62 \%$ dos gerentes da empresa ingerem bebidas alcoólicas, enquanto $38 \%$ não. Apesar da maioria dos gerentes ingerir bebidas alcoólicas, destaca-se o alto percentual dos que não consomem, 38\%. Esse resultado pode ser explicado, em parte, pelos programas sociais realizados pela empresa visando atender os funcionários com vícios nocivos à saúde, como o álcool e as drogas, lembrando que a simples ingestão de bebidas alcoólicas não caracteriza um vício.

Em relação às consultas médicas nos últimos três meses, percebe-se que $86 \%$ dos gerentes não se consultaram com algum médico nesse período. Quanto a licenças médicas, $100 \%$ dos gerentes informaram não as ter tirado nos últimos três meses. Apesar de a maioria dos gerentes não realizar atividades físicas durante a semana, nota-se que não houve casos de licença médica nos últimos três meses.

Em relação à pergunta que foi feita aos gerentes, referente à freqüência com que pensam em se demitir, a grande maioria, $81 \%$, respondeu que nunca pensou, seguida por $18 \%$ que responderam que raramente pensam e 
$1 \%$ freqüentemente. Constata-se que a grande maioria dos gerentes está relativamente satisfeita com o desempenho de suas funções ou não está tão mal a ponto de pensar em demissão.

\section{Qualidade de vida no trabalho}

A distribuição da amostra pelas dimensões da tarefa visou verificar a tarefa por meio de várias vertentes, de acordo com a percepção de cada gerente pesquisado da empresa. Utilizando como referência a variedade de habilidades, nota-se que $96 \%$ dos abordados consideram elevado o número de habilidades para a execução da sua função, enquanto $4 \%$ consideram médio. A identidade da tarefa mostra que $76 \%$ dos questionados consideram elevado o grau de exigência para a execução de um trabalho, identificável, do início ao fim, seguido por $13 \%$ que consideram baixo e $11 \%$ mediano. O significado da tarefa evidenciou que a grande maioria dos abordados, $81 \%$, considera médio o grau com que a sua tarefa afeta as outras pessoas, seja na empresa ou não, seguida por $11 \%$ que consideram baixo e $8 \%$ elevado. O inter-relacionamento, ou seja, o grau com que uma pessoa se relaciona no trabalho com outras pessoas para cumprir suas tarefas, evidenciou que quase a totalidade dos questionados, 95\%, considera elevado o seu próprio grau de inter-relacionamento, enquanto $5 \%$ deles consideram "médio". Por meio da autonomia, como forma de se dimensionar a tarefa, a pesquisa mostrou que $84 \%$ dos gerentes da empresa consideram elevado o seu grau de autonomia para a execução de suas tarefas, seguidos por $14 \%$ que consideram médio e $2 \%$ baixo. O feedback intrínseco, ou seja, o nível em que uma pessoa recebe informações sobre seu desempenho por meio da execução de sua própria tarefa, mostrou que 56\% dos abordados consideram elevado esse tipo de feedback, enquanto $44 \%$ consideram médio. O feedback extrínseco, ou seja, o nível em que um funcionário recebe informações sobre seu desempenho por meio de terceiros, sejam eles intra ou extra empresa, evidenciou que $90 \%$ dos questionados consideram elevado esse tipo de feedback, enquanto $8 \%$ consideram médio e $2 \%$ baixo.

A análise geral das dimensões da tarefa, também chamada de potencial motivacional da tarefa (PMT), conseguida pela média de todas as dimensões da tarefa analisadas, mostrou que $92 \%$ dos abordados possuem um elevado PMT e 8\% possuem um médio. É um bom resultado, pois mostra que a tarefa realizada pelos gerentes possui um elevado grau de motivação, considerando todas as suas dimensões, e isso é um fator positivo para a qualidade de vida no trabalho. 
Analisando a distribuição da amostra por satisfações específicas ou contextuais como um todo, através de uma média em relação a todas as satisfações consideradas, conclui-se que $93 \%$ dos gerentes pesquisados possuem um elevado grau no quesito satisfações específicas, enquanto 6\% possuem um médio grau e 1\% baixo; $92 \%$ dos gerentes possuem um elevado nível de satisfação em relação à possibilidade de crescimento, enquanto $7 \%$ possuem um médio nível e $1 \%$ baixo. Em relação à satisfação quanto à supervisão adequada, a pesquisa constatou que $92 \%$ dos gerentes possuem um elevado grau de satisfação, seguidos por $4 \%$ que possuem médio grau e $4 \%$ baixo. Para $90 \%$ dos questionados, a satisfação com a segurança é elevada, seguidos por $8 \%$ média e $2 \%$ baixa. Deve-se salientar que a Copasa-MG é uma empresa de economia mista onde o estado de Minas Gerais é seu maior acionista e os funcionários da empresa estão sob o regime trabalhista da CLT (Consolidação das Leis Trabalhistas). Segundo o grau de satisfação em relação à compensação pelo trabalho, percebe-se que $94 \%$ dos gerentes possuem uma elevada satisfação, $5 \%$ possuem uma média satisfação e $1 \%$ baixa. O nível de satisfação em relação ao ambiente social no qual o gerente está inserido mostrou que 96\% dos abordados possuem um elevado grau de satisfação, enquanto $3 \%$ possuem um médio grau e $1 \%$ baixo.

O estado psicológico crítico geral dos gerentes da empresa, calculado pela média das variáveis consideradas, evidenciou que $96 \%$ dos gerentes da empresa possuem um elevado grau de conhecimento crítico a respeito do seu trabalho, seguidos por $4 \%$ que possuem um médio grau. Esse resultado é muito positivo, pois mostra que quase a totalidade dos gerentes pesquisados está consciente sobre a importância do seu trabalho para o sucesso do negócio da empresa e sua responsabilidade sobre os resultados a serem obtidos. A distribuição da amostra pela percepção da significância do trabalho, por parte dos gerentes, mostrou que $94 \%$ dos questionados percebem, em grau elevado, a sua tarefa como significativa e valiosa, enquanto $6 \%$ percebem em grau médio. Essa análise mostra que a maioria dos gerentes sabe que sua tarefa é de grande importância para a empresa, o que é positivo tanto para o gerente quanto para a empresa. Trabalhar com tarefas importantes torna o próprio executor importante, o que também aumenta a sua responsabilidade na execução da própria tarefa, convergindo assim para uma maior produtividade para a empresa. Analisando a amostra por meio da percepção da responsabilidade pelos resultados, percebe-se que $93 \%$ dos abordados possuem um elevado grau de percepção da sua responsabilidade pelos resultados da empresa, enquanto 7\% possuem um médio grau. A percepção da responsabilidade pelos resultados do trabalho é também uma forma de se medir o compromisso dos gerentes com os 
resultados da empresa. Constatou-se ainda que $92 \%$ dos abordados possuem um elevado grau de conhecimento dos resultados do trabalho, enquanto $8 \%$ possuem um médio grau. Esse resultado pode ser considerado muito positivo, pois evidencia que os gerentes da Copasa-MG estão cientes dos resultados do seu trabalho, o que ajuda na manutenção da QVT e, daí, na qualidade dos serviços prestados, já que existe um parâmetro conhecido para se comparar.

A média geral dos resultados pessoais e de trabalho evidenciou que $93 \%$ dos mesmos possuem um elevado grau de satisfação com o seu trabalho, enquanto $6 \%$ possuem um médio grau e $1 \%$ baixo. Esse resultado também é muito positivo, pois mostra que a grande maioria dos gerentes está, de certa forma, satisfeita com a organização e motivada para executar suas tarefas.

\section{Estresse ocupacional}

Por meio de uma análise geral sobre as fontes de pressão e insatisfação dos gerentes da empresa, nota-se que, em média, $58 \%$ dos questionados consideram elevados esses fatores, enquanto $42 \%$ os consideram baixos. Assim, nota-se que as fontes de pressão encontram-se em níveis elevados, o que pode prejudicar a boa saúde e a produtividade dos profissionais no médio e longo prazos, caso já não estejam prejudicando. Quanto aos fatores intrínsecos ao trabalho, ou seja, fatores relacionados à jornada de trabalho, condição de trabalho, riscos inerentes à atividade profissional, a pesquisa mostra que $82 \%$ dos gerentes acreditam que tais fatores sejam de baixa pressão, mas $18 \%$ já pensam que sejam de elevada. Interessante observar que esse quesito, considerando os fatores de pressão citados, foi o único em que os gerentes da empresa consideraram, em sua maioria, de baixa pressão. Analisando o nível de pressão sob a ótica do papel gerencial, nota-se que $56 \%$ dos abordados consideram elevado esse tipo de pressão, enquanto $44 \%$ consideram baixo. Assim, o simples fato de ser gerente, para a maioria dos questionados, já é uma elevada fonte de pressão. O nível de pressão dos relacionamentos interpessoais mostrou que a maioria (81\%) dos gerentes considera esse um elevado fator de pressão e $19 \%$ consideram um baixo fator de pressão. Note-se que esse quesito mostrou ser uma das maiores fontes de pressão sobre os gerentes. Os relacionamentos interpessoais tornam-se assim um importante quesito a ser aprofundado pela Copasa-MG, visando obter um diagnóstico mais preciso dessa fonte de pressão, com o intuito de gerenciá-la. A própria carreira de gerente, para $58 \%$ dos abordados, é um elevado fator de pressão, enquanto para $42 \%$ é um baixo fator. Esse resultado pode ser explicado pelas mudanças ocorridas na organi- 
zação da empresa nos últimos anos, na qual o gerente de divisão absorveu as gerências de níveis inferiores, aumentando o seu âmbito de supervisão. A estrutura e o clima organizacional foram considerados como elevados fatores de pressão para $72 \%$ dos gerentes da empresa, enquanto $28 \%$ os consideraram baixos. O nível de pressão da interface casa-trabalho, ou seja, a conciliação da vida pessoal com a profissional, mostrou que para $62 \%$ dos gerentes essa fonte de pressão é considerada elevada, mas para $38 \%$ não.

A classificação da amostra pelo tipo de personalidade evidenciou que $54 \%$ dos gerentes questionados se enquadram no tipo A, ou seja, são pessoas apressadas, competitivas, ansiosas, que levam a vida em ritmo acelerado. $\mathrm{O}$ tipo de personalidade $\mathrm{B}$, que é caracterizado por pessoas que não sentem necessidade de impressionar terceiros, que são capazes de trabalhar sem agitação, relaxam sem sentimento de culpa e não padecem de impaciência ou de senso de urgência, é representado por $46 \%$ dos abordados. Pela distribuição da amostra segundo o locus de controle, nota-se que $74 \%$ dos questionados possuem locus interno, ou seja, são pessoas que possuem domínio sobre as coisas que acontecem ao seu redor e suas decisões e ações influenciam seus resultados pessoais. Tais pessoas tendem a ser menos vulneráveis ao estresse. As pessoas que possuem o locus de controle externo atribuem pouca influência própria sobre os eventos que ocorrem no seu meio, e esses eventos são considerados também fatores determinantes da maior parte dos seus resultados. De acordo com a pesquisa, $26 \%$ dos gerentes se enquadram no último locus. Assim, $62 \%$ dos gerentes da Copasa-MG estão propensos ao estresse. Esse elevado índice de propensão mostra que ações contra esse "mal" na empresa fazem-se necessárias, evitando assim que futuramente tais gestores sofram os males decorrentes desse infortúnio, prejudicando assim a produtividade da empresa.

Quanto aos sintomas físicos e mentais de estresse, as respostas dos gestores pesquisados evidenciam que em termos da saúde mental 93\% estão classificados como satisfatórios; já a saúde física dos gerentes da empresa está satisfatória para $100 \%$. Esse resultado é muito positivo, dado que no geral a saúde tanto física quanto mental dos gerentes da Copasa-MG está positiva. Interessante observar que, apesar da maioria dos gerentes não realizar atividades físicas durante a semana, quase todos, conforme respostas no questionário, apresentam uma boa saúde física.

Através de uma análise geral das estratégias de combates/defesa contra o estresse adotadas pelos gerentes da empresa, verifica-se que $78 \%$ dos mesmos possuem um elevado nível de utilização de tais estratégias e $22 \%$ possuem um baixo nível das mesmas. Observe-se que os gerentes da Copasa-MG estão expostos a elevados níveis de pressão; todavia, utilizam de forma freqüente 
técnicas de combate ao estresse, atenuando seus efeitos nocivos. Analisando a distração como forma de combate ao estresse, ou seja, através de atividades que servem de distração para a mente e o corpo dos gerentes, observa-se que, para $76 \%$ dos mesmos, esse é um método com elevado nível de utilização para o combate e/ou defesa contra o estresse, enquanto para o restante deles isso não se verificou. A racionalização dos eventos do ambiente mostra que para $73 \%$ dos gerentes da organização esse método possui um elevado nível de utilização frente ao estresse, enquanto $27 \%$ o consideram baixo. A gerência do tempo foi um método considerado de elevado nível de combate ao estresse para $92 \%$ dos abordados, enquanto os outros $8 \%$ o consideraram baixo. Logo, a gerência do tempo é o método mais utilizado pelos gerentes da empresa para combater o estresse. A distribuição da amostra pelo nível de combate ao estresse por meio de apoio social, ou seja, através do apoio das pessoas do convívio social dos gerentes, mostrou que $64 \%$ consideram esse método em nível elevado de combate ao estresse, enquanto $36 \%$ o consideram baixo.

\section{Considerações finais}

Este artigo descreveu e analisou o corpo gerencial de uma empresa pública pós-reestruturação produtiva no que diz respeito às variáveis de qualidade de vida no trabalho e de estresse ocupacional. Justificou-se a investigação em função dos diversos impactos que os sujeitos vêm sofrendo devido a necessidades de ordem tanto individual quanto grupal e organizacional, advindas das alterações promovidas em suas atividades e também nos significados das suas experiências de trabalho, resultando em desgastes na saúde dos indivíduos, tanto do ponto de vista físico como mental.

De uma maneira geral, a qualidade de vida dos pesquisados apresentase com níveis satisfatórios. No entanto, a variável "significado da tarefa" teve um comportamento diferente dos demais: 80\% dos gerentes concluíram ser mediana a importância da sua tarefa para a empresa. Tal resultado evidencia a necessidade de uma maior sensibilização da classe gerencial sobre a natureza da sua função e os resultados almejados pela empresa.

Apesar de 62\% dos gerentes serem propensos ao estresse (em função dos tipos de personalidade mapeados), poucos sentem ou confidenciam seus sintomas físicos e mentais. Interessante observar que apesar de somente 7\% dos gerentes sentirem níveis insatisfatórios de saúde mental e nenhum gerente sentir níveis insatisfatórios de saúde física, a grande maioria dos abordados (78\%) utiliza estratégias variadas de combate ao estresse em nível elevado. 
Note-se que a análise conjunta dos resultados da pesquisa aponta para uma realidade de estresse: se os sintomas de estresse estão baixos, questiona-se por que a grande maioria dos gerentes os combate, ou melhor, se ele praticamente não existe, não haveria razões para dele se defender.

Percebe-se, portanto, que uma atenção especial se faz necessária para a identificação, a desmistificação e o monitoramento do estresse ocupacional entre os gerentes da Copasa-MG. Isso pode se dar aliando-se esforços de pesquisa e aprendizagem no que tange a investigações mais específicas de diagnóstico e também comparativas, considerando-se gerentes e não-gerentes, assim como outras organizações públicas do mesmo estado que passaram pelo processo de reestruturação e as de outros estados que implementaram mudanças semelhantes na gestão de seus recursos.

Diante dos resultados da pesquisa, sugere-se à empresa estruturar e desenvolver políticas e práticas de gestão de pessoas voltadas para a minimização dos malefícios causados pelo "choque de gestão" nos indivíduos. Isso diz respeito tanto a gerentes como não-gerentes e engloba ações primordialmente relacionadas a treinamento e desenvolvimento de pessoal, a avaliação funcional (desempenho, resultados e potencial), e a cargos e carreiras. Percebe-se que tais atividades são recursos adjacentes à reestruturação produtiva em organizações públicas, pois referem-se à gestão da força de trabalho e à mediação de conflitos.

\section{Referências bibliográficas}

AKTOUF, O. Prefácio. In: DAVEL, E.; MELO, M. C. O. L. (Orgs.). Gerência em ação. Rio de Janeiro: FGV, 2005.

ALBRECHT, K. Stress and the manager: making it work for you. New Jersey: Prentice Hall, 1979.

ALDWIN, C. et al. Depression and coping in stressful episodes. Journal of Applied Psychology. v. 90, p. 439-447, 1981.

ÁLVARES, T. As 25 melhores empresas do país. Gazeta Mercantil, São Paulo, 8 ago. 2005, Nacional, Caderno A, p. 5.

BARNARD, C. As funções do executivo. São Paulo: Atlas, 1971.

BERNDT, A.; COIMBRA, R. As organizações como sistemas saudáveis. Revista de Administração de Empresas, jul./ago. 1995. 
BRAVERMAN, H. Trabalho e capital monopolista. Rio de Janeiro: Zahar, 1981.

BRUYNE, P. et al. Dinâmica da pesquisa em ciências sociais. Rio de Janeiro: Francisco Alves, 1977.

CASTRO, A. P. et al. Manual de gestão de pessoas e equipes: estratégias e tendências. São Paulo: Gente, 2002.

COOPER, C. L. et al. Occupational stress indicator management guide. Windsor: NFER-Nelson, 1988.

et al. Work psychology — understanding human behavior in the workplace.

London: Pitman, 1995. et al. Teachers under pressure: stress in profession. Routledge, 1996.

CUMMINGS, T.; COOPER, C. L. . A cybernetic framework for the study of occupational stress. Human Relations, v. 32, 1979.

DAVEL, E.; MELO, M. C. O. L. Singularidades e transformações no trabalho dos gerentes. In: (Orgs.). Gerência em ação. Rio de Janeiro: FGV, 2005.

DAVIS, K.; WERTHER, W. Administração de pessoal e recursos humanos. São Paulo: McGraw-Hill, 1983.

DEMO, P. Complexidade e aprendizagem: a dinâmica não linear do conhecimento. São Paulo: Atlas, 2002.

DEWE, P. J. Applying the concept of appraisal to work stressors: some exploratory analysis. Human Relations, v. 45, n. 2, p. 143-164, 1992.

DRUCKER, P. O gerente eficaz. Rio de Janeiro: LTC, 1967.

FAYOL, H. Administração industrial e geral. São Paulo: Atlas, 1990.

FRIEDMAN, M. D.; ROSENMAN, R. H. Type A behavior and your heart. New York: Knopf, 1974.

GOLDBERG, P. A saúde dos executivos. Rio de Janeiro: Guanabara, 1978.

GRUM, R. Desemprego gerencial e mudança nos sistemas simbólicos imperantes nas classes médias brasileiras. In: ENCONTRO NACIONAL DA ANPOCS, 19., Caxambu, 1995. Anais... Caxambu: Anpocs, 1995.

HACKMAN, J. R.; OLDHAM, G. R. Development of the job diagnostic survey. Journal of Applied Psychology, v. 60, n. 2, p. 159-170, 1975.

HILL, L. A. Novos gerentes: assumindo uma nova identidade. São Paulo: Makron Books, 1993. 
HUSE, E.; CUMMINGS, T. Organization development and change. St. Paul: West, 1985.

JAMAL, M. Relationship of job stress and type A-behavior to employee's job satisfaction, organizational commitment, psychosomatic health problems and turnover motivation. Human Relations, v. 43, n. 18, p. 727-738, 1990.

KATZ, R. As habilitações de um administrador eficiente. Coleção Harvard de Administração, v. 1, p. 57-92. São Paulo: Nova Cultural, 1986.

KERLINGER, F. Metodologia da pesquisa em ciências sociais: um tratamento conceitual. São Paulo: EPU/Edusp, 1980.

LIKERT, R. Novos padrões de administração. São Paulo: Pioneira, 1971.

LIMA-FILHO, D. O. et al. Reforma administrativa e resistências externas: um estudo de caso. Revista de Administração Pública, Rio de Janeiro, v. 39, n. 1, p. 123-138, jan. 2005.

LIPPITT, G. L. Quality of work life: organization renewal in action. Training and Development Journal, v. 32, n. 1, p. 4-10, jul. 1987.

McCLELLAND, D. C. O poder é o grande motivador. São Paulo: Nova Cultural, 1987.

MELO, M. C. O. L. O gerente e a função gerencial nas organizações pós-reestruturação produtiva. In: ENCONTRO NACIONAL DE ESTUDOS DO TRABALHO, 6., São Paulo, 1999. Anais... São Paulo: Abet, 1999.

et al. Gerenciando os gerentes: reflexões e desafios para os profissionais

de Recursos Humanos. In: FÓRUM CRITEOS, Porto Alegre, 2005. Anais... Porto Alegre: UFRGS, 2005.

MINTZBERG, H. Trabalho do executivo: o folclore e o fato. Coleção Harvard de Administração, v. 3, p. 5-37. São Paulo: Nova Cultural, 1986.

MORAES, L. F. R.; KILIMNIK, Z. Comprometimento organizacional, qualidade de vida e stress no trabalho: uma abordagem de diagnóstico comparativo. Relatório de Pesquisa. Belo Horizonte: UFMG, 1994.

MORGAN, G. Imagens da organização. São Paulo: Atlas, 1996.

MOTTA, P. R. Gestão contemporânea: a ciência e a arte de ser dirigente. Rio de Janeiro: Record, 1995.

NADLER, D.; LAWLER, E. Quality of work life: perspectives and directions. Organization Dynamics, v. 1, n. 11, p. 20-30, Winter 1983.

PEREIRA, C. S. et al. Dimensões funcionais da gestão de pessoas. Rio de Janeiro: FGV, 2003. 132 p. 
RODRIGUES, S. B. O chefinho, o telefone e o bode: autoritarismo e mudança cultural no setor de telecomunicações. 1991. Tese (Professor Titular) - Belo Horizonte, UFMG.

ROOTER, J. B. Generalised expectations for internal versus external control of reinforcement. Psychology Monograph, n. 80, 1966.

ROULEAU, L. Les reestructurations d'entreprise: quelques points de repère. Management International, v. 5, n. 1, p. 45-52, 2000.

. Gerentes e repertórios de identidade em contexto de reestruturação organizacional. In: DAVEL, E.; MELO, M. C. O. L. (Orgs.). Gerência em ação. Rio de Janeiro: FGV, 2005.

SCHEIN, E. Planejamento e desenvolvimento de recursos humanos: fatores de eficácia das organizações. Cadernos de Recursos Humanos, Belo Horizonte, v. 3, n. 5, p. 13-39, 1994.

SELYE, H. The general adaptation syndrome and the diseases of adaptation. Journal of Clinical Endocrinology, v. 6, 1946.

. Stress without distress. USA: New American Library, 1974.

SIMON, H. A. Comportamento administrativo. Rio de Janeiro: FGV, 1965.

TAYLOR, F. W. Princípios de administração científica. São Paulo: Atlas, 1970.

THÉRIAULT, R. Qualité de la vie au travail: implications sur la gestion de la rémunerátion. In: BOISVERT, M. La qualité de la vie au travail. Ottawa: Agence d'Arc, 1980. p. 67-83.

TOHÁ, C.; SOLARI, R. La modernización del estado y la gerencia publica. Santiago, Chile: Fundación Friedrich Ebert, 1997.

VON SPERLING, L. Expectativas e estratégias de auto-regulação dos gerentes frente a processos de reestruturação e modernização: um estudo em organizações da administração pública indireta. 2002. Dissertação (Mestrado em Administração) — Belo Horizonte, UFMG.

WALTON, R. E. Quality of working life: what is it? Sloan Management Review, v. 15, n. 1, p. 11-21, Dec. 1973.

WEBER, M. Ensaios de sociologia. Rio de Janeiro: Zahar, 1946.

WESTLEY, W. A. Problems and solutions in the quality of working life. Human Relations, v. 32, n. 2, p. 111-123, Feb. 1979. 